\title{
Exploring the effect of the spatial scale of fishery management
}

\author{
Nao Takashina ${ }^{\mathrm{a}, *}$, Marissa L. Baskett ${ }^{\mathrm{b}}$ \\ a Department of Biology, Faculty of Sciences, Kyushu University, 6-10-1, Hakozaki, Fukuoka 8128581, Japan \\ ${ }^{\mathrm{b}}$ Department of Environmental Science and Policy, University of California, Davis, One Shields Ave, Davis, CA 95616, United States
}

\section{H I G H L I G H T S}

- We explore the effect of spatial scale of fishery management in a bioeconomic model.

- Finer spatial scales of management can significantly improve optimal fishery profit.

- Profit increases nearly linearly with management scale for uncorrelated landscapes.

- Profit has diminishing returns with management scale for autocorrelated landscapes.

- An intermediate optimal management scale is more likely for autocorrelated landscapes.

\section{A R T I C L E I N F O}

\section{Article history:}

Received 23 September 2015

Received in revised form

6 November 2015

Accepted 10 November 2015

Available online 22 November 2015

Keywords:

Bioeconomic model

Management scale

Marine reserves

\begin{abstract}
A B S T R A C T
For any spatially explicit management, determining the appropriate spatial scale of management decisions is critical to success at achieving a given management goal. Specifically, managers must decide how much to subdivide a given managed region: from implementing a uniform approach across the region to considering a unique approach in each of one hundred patches and everything in between. Spatially explicit approaches, such as the implementation of marine spatial planning and marine reserves, are increasingly used in fishery management. Using a spatially explicit bioeconomic model, we quantify how the management scale affects optimal fishery profit, biomass, fishery effort, and the fraction of habitat in marine reserves. We find that, if habitats are randomly distributed, the fishery profit increases almost linearly with the number of segments. However, if habitats are positively autocorrelated, then the fishery profit increases with diminishing returns. Therefore, the true optimum in management scale given cost to subdivision depends on the habitat distribution pattern.
\end{abstract}

(c) 2015 Elsevier Ltd. All rights reserved.

\section{Introduction}

The importance of spatial scale has been well recognized in many fields of ecology (Levin 1992), such as species-area relationships, maps of species richness, and conservation planning (Palmer and White, 1994; Schwartz, 1999; Margules and Pressey, 2000; Turner and Tjørve, 2005; Hurlbert and Jetz, 2007). Spatially explicit approaches to ecosystem management introduce a management scale overlaid on the natural spatial scale of ecological processes. Specifically, managers must decide how much to subdivide the area under concern: from implementing a uniform approach across the region to considering a unique approach in each of hundreds of patches and everything in between. This scale of management assessment and implementation affects the ability to achieve management goals. For example, analysis of range-map data at inappropriately fine resolutions might lead to the identification of erroneous

\footnotetext{
* Corresponding author. Tel: +8192642 2642; fax.: +8192642 2645 .

E-mail addresses: nao.takashina@gmail.com (N. Takashina), mlbaskett@ucdavis.edu (M.L. Baskett).
}

"biodiversity hotspots" with overly optimistic estimates of species representation in reserves and potentially invalid complementarity sets for identifying conservation priorities (Hurlbert and Jetz, 2007).

Ecosystem-based fisheries management (EBFM) is an inherently spatially explicit approach to fisheries management, including the implementation of marine reserves, or no-take zones (Pikitch et al., 2004). Marine reserves goals range from conserving species to support sustainable fisheries management (Leslie, 2005; Lester et al., 2009). Even without reserves, EBFM typically involves a spatially explicit approach to harvest decision in terms of zonal allocations of fishing effort (Francis et al., 2007), which can increase fishery profit over spatially uniform management if appropriately based on habitat distribution and connectivity (Rassweiler et al., 2012). However, few studies explicitly considered the effect of the choice of spatial scale in spatial fishery management on achieving management goals.

Under spatial fisheries management, managers must choose a management scale to define a management unit (i.e., zoning unit), and fishing regulations such as entry limitation and establishment of reserves occur within these zoning units (Cancino et al., 2007; White 
and Costello, 2011). For example, the concept of setting variable harvest rates over space was implemented for co-occurring fisheries of less productive and productive species in the US west coast, such as yellowtail and canary rockfish (Francis, 1986) and yelloweye rockfish and lingcod (Dougherty et al., 2013). Spatial management through a fine filter enables managers to allocate fishing efforts and reserves more flexibly compared to management through a coarse filter, but a finer filter imposes greater complexity on the decisionmaking process and enforcement. For territorial user rights fisheries (TURFs), coarser management scales increase achievement of optimal harvest due to the greater degree of ownership and lower competition (White and Costello, 2011). However, for fisheries under topdown control such as the case where federal level government decisions determine individual fishing effort, the appropriate management scale might change because competition between management units does not occur.

To investigate how the choice of spatial management scale affects fishery and ecological outcomes such as optimal fishery profit, biomass, fishery effort, and the fraction of habitat in marine reserves, we construct a spatially explicit bioeconomic model that follows an age-structured harvested population. Using two California species, cabezon (Scorpaenichthys marmorata) and red abalone (Haliotis rufescens), we compare two spatial management strategies: allocating reserve or non-reserve patches with a uniform fishing rate versus allocating fishing rate in each patch, where allocation within the management scale maximizes fishery profit. We then investigate the relationship between the spatial scale of management and the above-mentioned fishery and ecological outcomes under varying degrees of autocorrelation in the habitat, which determines the spatial scale of habitat.

\section{Methods}

We aim to construct the simplest possible model that allows us to quantify the relationship between the choice of spatial management scale and our metrics for fishery and ecological outcomes. As detailed below, the managed population occurs in a naturally patchy habitat, where the choice of management scale relative to the natural habitat patch size determines its effect on population dynamics. We explore different values of spatial autocorrelation in habitat patches to model different levels of natural patchiness. Larval dispersal connects the patches, where populations then experience density-dependent recruitment. Post-settlement individuals remain within habitat patches (i.e., a relatively sedentary species) according to an agestructured model with density-independent natural and harvest mortality; the structured population dynamics allow us to determine the effect of management decisions on population biomass and biomass yield. To model top-down control given a particular management scale, the fishery optimizes profit across the entire habitat based on management-patch-specific effort allocation, with two approaches. First, management patches have either zero effort (reserves) or harvest, with the same effort in all harvested patches and both this effort level and which patches are harvested are chosen to maximize yield (uniform effort, or UE, strategy); this approach models the optimal use of reserves in fishery management, with no further spatially explicit management beyond reserve designation. Second, the amount of effort in each management patch (including the possibility of zero effort) is chosen to maximize yield (fine-tuned effort, or FE, strategy); this approach models a fully spatially explicit management approach. We then determine the effect of management scale on effort and profit as our fishery outcomes as well as population biomass and fraction of the habitat in marine reserves as our ecological outcomes.

\section{Environmental and management scale}

The target species population occurs along a coastline where we approximate the geographic landscape by a one-dimensional patchy environment with different patterns of autocorrelation in habitat quality. The minimum size of habitat defines the environmental scale that determines the population dynamics. Whether or not fishing occurs in a given location depends on a separate management scale (Fig. 1). We define the management scale as the size of a minimum management unit where fishing effort is uniform within the region. We assume that the minimum management scale is the environmental scale. The environmental scale inherently depends on ecological and physiological characteristics of a species and geomorphological patterns (Levin, 1992). The management scale depends on managers or fishermen based on, for example, assessment data or range maps (Hopkinson et al., 2000, Hurlbert and Jetz, 2007), and it characterizes the spatial fishery management. Here we set the environmental scale (minimum habitat patch size) to $1 \mathrm{~km}$ to match the minimum environmental scale of the target species in their post-larval home

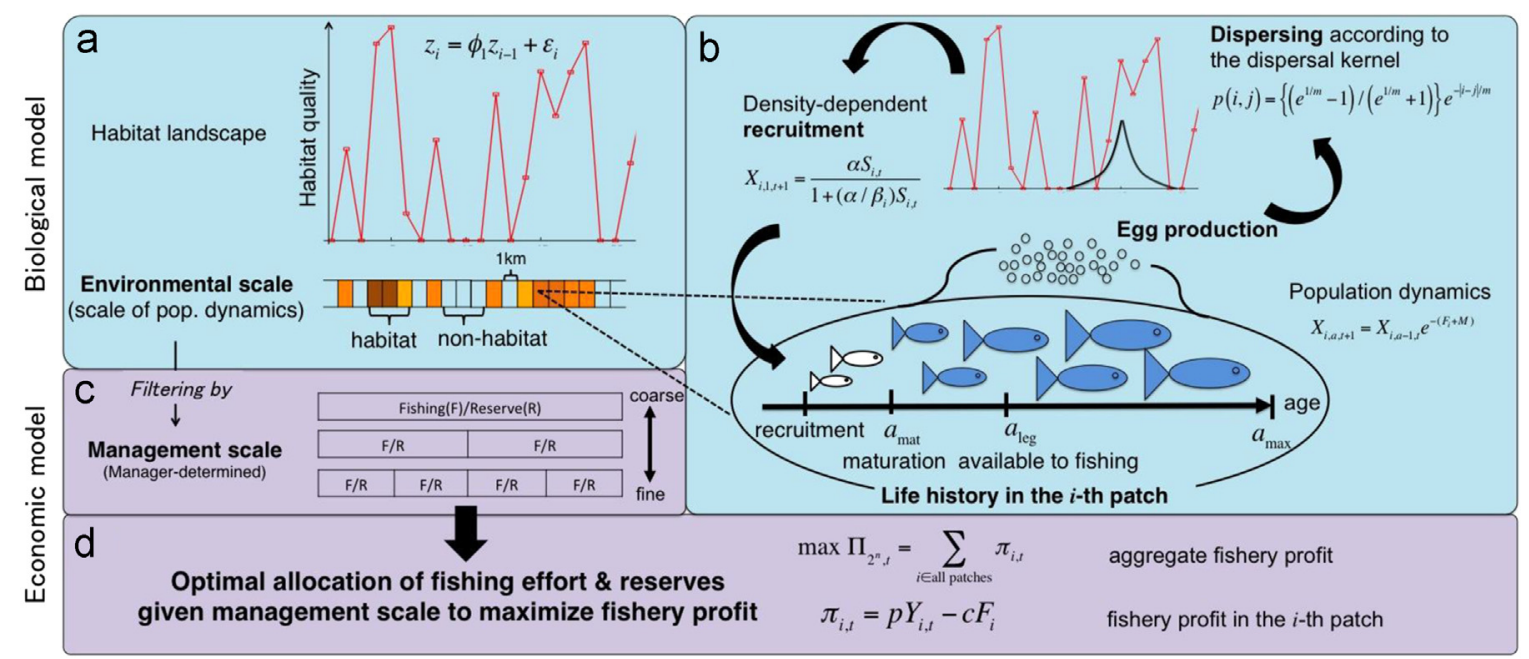

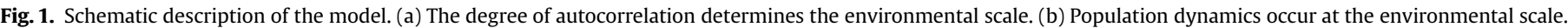

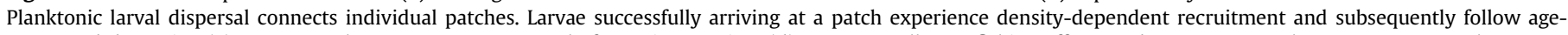

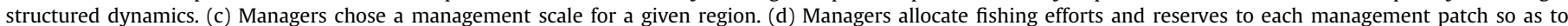
maximize fishery profit for each given management scale. 
range (i.e. $<1 \mathrm{~km}$ adult movement). The management scale can then be $2^{0}, 2^{1}, \cdots$, or $2^{n}$ times larger than the environmental scale where $n$ is the number of subdivisions. Hereafter, we use "habitat patch", or, briefly, "patch" to indicate the environmental scale, and we explicitly refer to "management patch" when discussing a management location.

\section{Habitat landscape}

We construct an $n$-patch habitat landscape (relative carrying capacity $z_{1}, \cdots, z_{n}$ ) with the auto-regressive model (AR(1) model) to generate various autocorrelations patterns between patches in a manner analogous to how they are often measured in field data (Dale and Fortin, 2009). Increasing positive autocorrelation indicates increasing similarity between neighboring patches and therefore increasing habitat scale. With the degree of autocorrelation $\phi_{1}$ and white noise $\varepsilon_{i}$ with 0 mean and a variance of 1 , we employ the AR(1) model

$z_{i}=\phi_{1} z_{i-1}+\varepsilon_{i}$

We regard the $i$-th patch to be habitat if $z_{i}>0$ and non-habitat if $z_{i} \leq 0$. Specifically we define $z_{i}$ as $z_{i}=\max \left(\phi_{1} z_{i-1}+\varepsilon_{i}, 0\right)$, and any individuals that disperse to non-habitat do not survive.

\section{Population dynamics}

In the bioeconomic model underlying our analysis, postsettlement age classes experience natural mortality at a rate $M$ and, after growing to the age at legal size $a_{\text {leg }}$, fishing mortality at a patch-specific rate $F_{i}$. The dynamics for the population abundance $X_{i, a, t}$ in the $i$-th patch at age $a$ and time $t$ (year) in each time step are then

$X_{i, a, t+1}=\left\{\begin{array}{c}X_{i, a-1, t} e^{-M}, 2 \leq a<a_{\mathrm{leg}} \\ X_{i, a-1, t} e^{-\left(F_{i}+M\right)}, a_{\mathrm{leg}} \leq a \leq a_{\max },\end{array}\right.$

given maximum age $a_{\max }$.

We convert age to size to both calculate population biomass as one of our output metrics and to calculate larval production in the population dynamics. We obtain the length at age $L_{a}$ using the von Bertalanffy growth equation, given the asymptotic length $L_{\infty}$, the age at $0 \mathrm{~cm} a_{0}$, and growth rate $k: L_{a}=L_{\infty}\left(1-e^{-k\left(a-a_{0}\right)}\right)$. We then obtain the biomass for each age $W_{a}$ using the allometlic relationship with constants $b_{1}$ and $b_{2}, W_{a}=b_{1} L_{a}{ }^{b_{2}}$. Total biomass in

Table 1

Cabezon (Scorpaenichthys marmorata) parameters, following the parameterization in White et al. (2010).

\begin{tabular}{llll}
\hline Parameter & Description & Value & Source $^{*}$ \\
\hline$L_{\infty}$ & Maximum size & $62.12 \mathrm{~cm}$ & $\mathrm{a}$ \\
$k$ & Growth rate & $0.18 \mathrm{~cm} /$ year & $\mathrm{a}$ \\
$a_{0}$ & Age at $0 \mathrm{~cm}$ & -1.06 year & $\mathrm{a}$ \\
$b_{1}$ & Coefficient in length-to- & $9.2 \times 10^{-6}$ & $\mathrm{a}$ \\
& weight relationship & & \\
$b_{2}$ & Exponent in length-to-weight & 3.187 & $\mathrm{a}$ \\
& relationship & & \\
$E_{a}$ & Fecundity-at-weight & $\left(15.3 W_{a}+27.3\right) \times 10^{3}$ eggs & $\mathrm{b}$ \\
$a_{\max }$ & Maximum age & 15 years & $\mathrm{a}, \mathrm{c}$ \\
$a_{\text {mat }}$ & Age at maturity & 3 years & $\mathrm{a}$ \\
$a_{\text {catch }}$ & Age available to fishing & 4 years $(38.1 \mathrm{~cm})$ & $\mathrm{d}$ \\
$M$ & Natural mortality rate & $0.25 /$ year & $\mathrm{a}$ \\
$\bar{m}$ & Mean larvae dispersal & $100 \mathrm{~km}$ & $\mathrm{c}$ \\
& distance & &
\end{tabular}

*a. Cope and Punt (2005); b. O'Connell (1953); c. White et al. (2010); d. CDFW (2014b) the system at time $t, B_{t}$, is the sum of the biomass over all age classes and patches, $B_{t}=\sum_{i} \sum_{a} W_{i, a} X_{i, a, t}$. For reproduction, we convert age to size to fecundity $E_{a}$, where sexually matured individuals (age $a \geq a_{\text {mat }}$ ) produce larvae after the fishing season. In cabezon, we use a fecundity-at-weight relationship to calculate $E_{a}$ (Table 1 ), and in abalone we use a fecundity-at-length relationship to calculate $E_{a}$ (Table $\mathrm{A} 1$ ). Total reproductive output is then $R_{i, t}=\sum_{a \operatorname{mat}}^{a \max } E_{a} X_{i, a, t}$.

We assume a sessile post-settlement stage where all connectivity between patches occurs through larval dispersal. To model this dispersal we introduce a discretized analog of the Laplacian kernel, which represents the probability $p(i, j)$ that a larva is transported from $i$-th patch to $j$-th patch by ocean currents. Specifically, we start with an exponentially decreasing probability with distance from the larval origin $p(i, j) \propto e^{-|i-j| / m}$ given integers $i$ and $j$ (Botsford et al., 2001; Kaplan, 2006; Lockwood et al., 2002), and choose the proportionality coefficient so as to satisfy $\sum_{j=-\infty}^{j=\infty} p(i, j)=1$. The settlement probability is then:

$p(i, j)=\left\{\left(e^{1 / m}-1\right) /\left(e^{1 / m}+1\right)\right\} e^{-|i-j| / m}$,

where $m$ is a non-dimensional quantity that determines the migration ability of the species, such that the mean dispersal distance is $\bar{m}=2 e^{1 / m} /\left(e^{1 / m}+1\right)\left(e^{1 / m}-1\right)$. All larvae that settle outside a habitat patch die, i.e., $p(i, k)=0$, for $k$ outside the habitat.

Density-dependent Beverton-Holt survivorship occurs among the total number of larvae (settlers) $S_{i, t}=\sum_{j} R_{j, t} p(i, j)$ arriving at the $i$-th patch at the end of the fishing season in time $t$. Specifically, given the maximum settler survival rate $\alpha$ and the carrying capacity in the $i$-th patch $\beta_{i}=z_{i} K$ (where $K$ is the baseline carrying capacity of one environmental patch with the value $10^{4}$ ), the number of recruits (age class 1 ) at time $t+1$ and location $i$ is:

$X_{i, 1, t+1}=\frac{\alpha S_{i, t}}{1+\left(\alpha / \beta_{i}\right) S_{i, t}}$

\section{Fishery dynamics}

The manager's allocation of fishing effort among the management patches depends on the single management scale and the goal of maximizing the equilibrium aggregate fishery profit $\Pi_{2^{n}}^{*}$ under the given fishing strategy (see below for two strategies), where $2^{n}$ indicates the number of management patches. The aggregate fishery profit at time $t, \Pi_{2^{n}, t}$ is the sum of the management patch-specific profits, $\pi_{i, t}$ over all patches:

$\Pi_{2^{n}, t}=\sum_{i} \pi_{i, t}$.

The patch-specific fishery profit $\pi_{i, t}$ is the fishery revenue (product of the price $P$ and biomass yield in the $i$-th patch at time $t, Y_{i, t}$ ) minus the harvest cost (product of per-patch cost of fishing mortality $c$ and fishing effort in the $i$-th patch $F_{i}$ ):

$\pi_{i, t}=P Y_{i, t}-c F_{i}$.

Given the biomass of legal-sized fish $\left(a \geq a_{\text {leg }}\right)$ in the $i$-th patch at time $t, B^{\text {leg }}{ }_{i, t}=\sum_{a \operatorname{leg}}^{a \max } W_{a} X_{i, a, t} F_{i}$, the yield in the $i$-th patch at time $t, Y_{i, t}$, is

$Y_{i, t}=\frac{B^{\operatorname{leg}}{ }_{i, t} F_{i}\left(1-e^{-\left(F_{i}+M\right)}\right)}{F_{i}+M}$

(Rassweiler et al., 2012).

We explore two optimal fishing strategies: (i) uniform effort strategy (UE strategy), and (ii) fine-tuned effort strategy (FE strategy). For the UE strategy, optimization occurs via allocation of fishing grounds $\left(A_{i}=1\right.$ in management patch $\left.i\right)$ and zero effort or no-take reserve if the patch is habitat $\left(A_{i}=0\right.$ to indicate a management patch with zero fishing effort) in each of the $2^{n}$ 
management patches given a single fishing effort $F$ on all open patches. Then the UE strategy achieves an optimization of aggregate fishery profit by choosing $2^{n}+1$ parameters $\left(A_{1}, A_{2}, \cdots, A_{2^{n}}, F\right)$ together so as to maximize the objective function at equilibrium:

$$
\max _{A, F} \pi_{2^{n}}^{*}=\max _{A, F} \sum \pi_{i}^{*},
$$

where $\pi_{i}^{*}$ represents management patch-specific profit at equilibrium. For the FE strategy, optimization occurs via designating a different fishing mortality $F_{i}$ in each of $2^{n}$ management patch $\left(F_{1}, F_{2}, \cdots, F_{2^{n}}\right)$, where $F_{i}=0$ in management patches that include habitat patch(es) represent cases where reserves are part of the management strategy. The objective function for the FE strategy is then

$\max _{F} \sum \pi_{i}^{*}$

Because it allows finer tuning of effort control, the FE strategy will inevitably outperform the UE strategy in terms of fishery profit, but it might be more costly to implement (see Discussion). Appendix S1 describes the two algorithms in more detail.

Note that if fishing occurs in a non-habitat patch or unproductive habitat with a small carrying capacity, then it may result in a cost of $c F_{i}$, or a negative profit in the patch on the environmental scale, but on the management scale all management patches satisfy $\pi_{i, t} \geq 0$. While our investigation of management scale does not account for effort elimination within unprofitable environmental patches as a finer-scale management does or as might occur through fisher behavior (e.g., fishers eventually noticing and avoiding non-habitat patches as they fish within a management unit), this is an effect that the manager tends to avoid nonproductive habitats given a fixed management scale. Also, the negative profit may serve, in practice, as an approximated cost associated with coarse-filtered management (e.g., ineffective initial searching due to an unspecified/broad management unit scale).

\section{Model parameterization}

We parameterize the model based on two example species in the California coast, cabezon (Scorpaenichthys marmorata) and red abalone (Haliotis rufescens), that have a relatively sedentary adult phase (adult home range $<1 \mathrm{~km}$ ) and differ in their larval dispersal distance. These two species are economically important nearshore species and are expected to benefit from spatial fisheries management (CDFW, 2014a). For simplicity we define $P$ (price/kg) as 1 and $c$ (cost/fishing effort) as a constant value (3000 in the main text; we investigate the parameter dependence in Appendix S2); our focus is on relative qualitative trends across varying management scales. We present results for cabezon in main text and for red abalone in Appendix S2 for demonstrating qualitatively robust results across these life histories (see Table 1 for cabezon and Appendix Table S1 for red abalone for the parameter values used in the analysis).
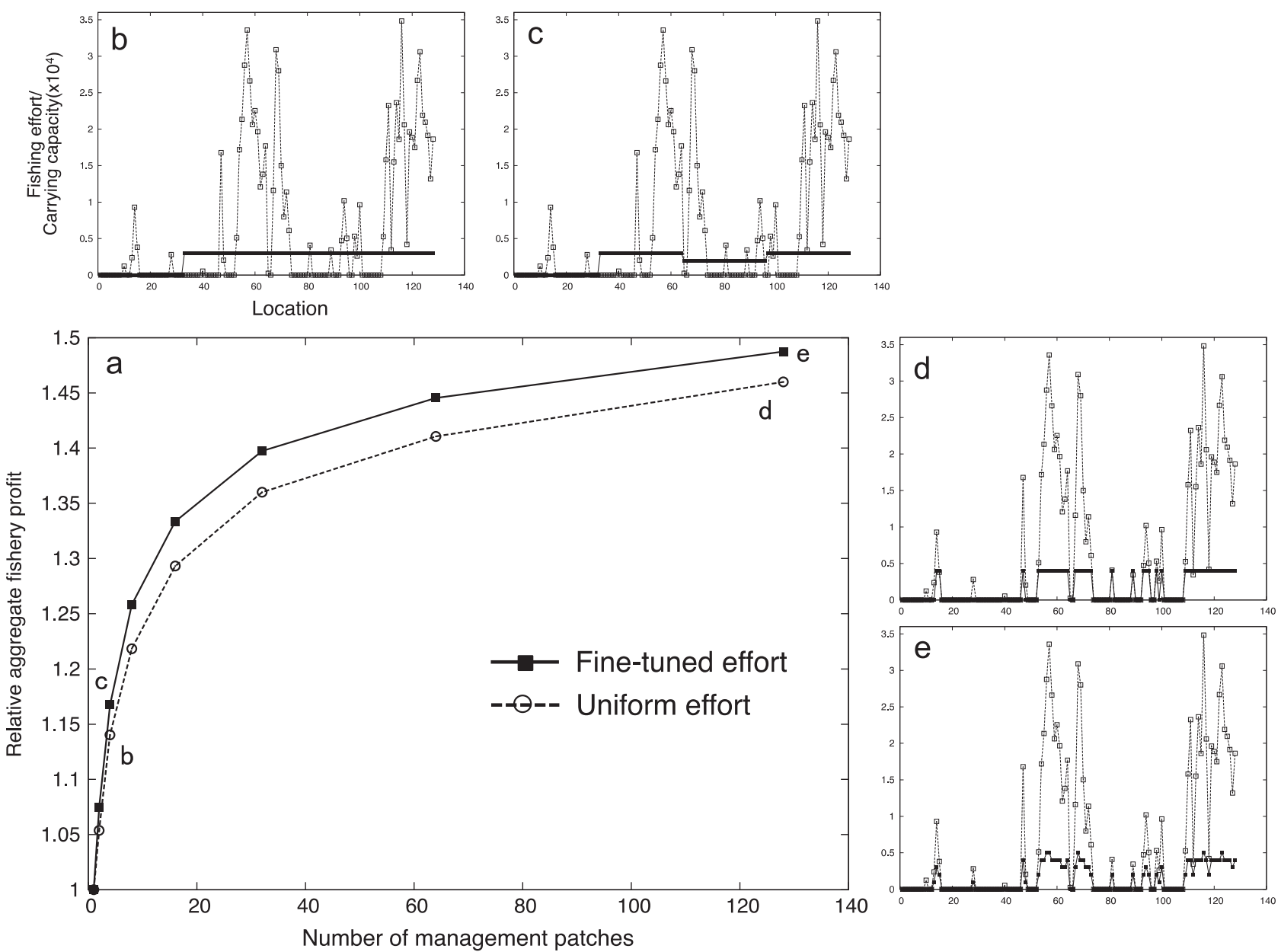

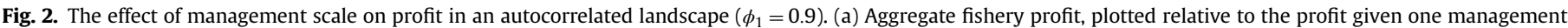

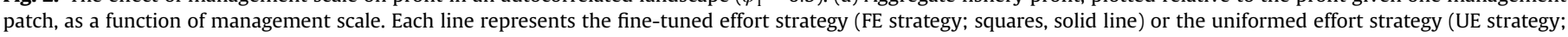

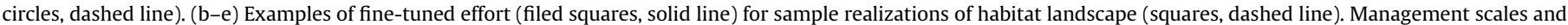
fishing strategies in each panel correspond to notations in the panel (a). 


\section{Analysis}

We investigate the effect of the different management scales on the aggregate fishery profit, total population biomass, fishing mortality rate for the UE strategy and average fishing mortality rate over nonreserve patches for the FE strategy, and the fraction of marine reserves, defined as [the number of habitat patches with no fishing mortality]/ [the total number of habitat patches]. We consider a coastline containing $2^{7}$ patches for the environmental scale. Therefore, the feasible set of management scales is $\left\{2^{7} \mathrm{~km}, 2^{6} \mathrm{~km}, \cdots, 2^{0} \mathrm{~km}\right\}$ and the corresponding set of the number of management patches is $\{1,2, \cdots, 128\}$. We show the average value over 100 simulation trials, where the AR(1) model randomly generates a different landscape in each simulation run. In the simulations, we only consider the practically relevant cases where the fishery is profitable.

\section{Results}

\subsection{Spatial fisheries management in positively autocorrelated landscapes}

Because we do not account for a cost to subdivision, applying a finer management scale always increases the net benefit of fishing regardless of the fishing strategy (Fig. 2; note that we discuss the reason for this and other outcomes in the Discussion below). When the habitat landscape is positively autocorrelated $\left(\phi_{1}=0.9\right.$ in Eq. (1)), the relative aggregate fishery profit increases with a finer management scale but with diminishing returns (Fig. 2a). The FE strategy always outperforms the UE strategy, but both show the same qualitative trend of diminishing returns with finer management scale. In addition, the effort distribution of the FE strategy is, by definition, more complex than that of the UE strategy (e.g., filed squares and solid line in Fig. 2e vs. 2d).

The total population biomass decreases as management scale becomes finer (Fig. 3a), and the decline is more rapid under the FE strategy than the UE strategy. Initially, the reserve fraction increases rapidly, then it quickly saturates (Fig. 3b). The UE strategy always requires a larger reserve fraction than the FE strategy for optimal profit. Fishing mortality (Fig. 3c) increases with an increasing number of management patches at a decreasing rate. The UE strategy always requires higher fishing mortality rate than the FE strategy for optimizing profit.

\subsection{Spatial fisheries management in uncorrelated landscapes}

Without autocorrelation ( $\phi_{1}=0$ in Eq. (1); white noise), fishery profit shifts to a near linear function of management scale (Fig. 4a, FE strategy; the UE strategy shows an analogous qualitative trend). In other words, increasing the number of management patches no longer exhibits diminishing returns in fishery profit. Relative biomass initially increases with an increasing number of management patches when that number is small, but after that it declines almost linearly as the number of management patches increases (Fig. 4b). Reserve fraction also peaks at an intermediate management scale, but at a greater number of patches than biomass (Fig. 4c). Fishing mortality initially decreases with an increasing number of management patches when that number is small, then subsequently increases almost linearly (Fig. 4d).

\subsection{Management efficacy and parameter sensitivity}

Looking beyond aggregate fishery profit to a question of how fisheries can effectively distribute fishing effort, the relative fraction of unprofitable patches declines with an increasing number of management patches (Fig. 5, FE strategy). This decline is more
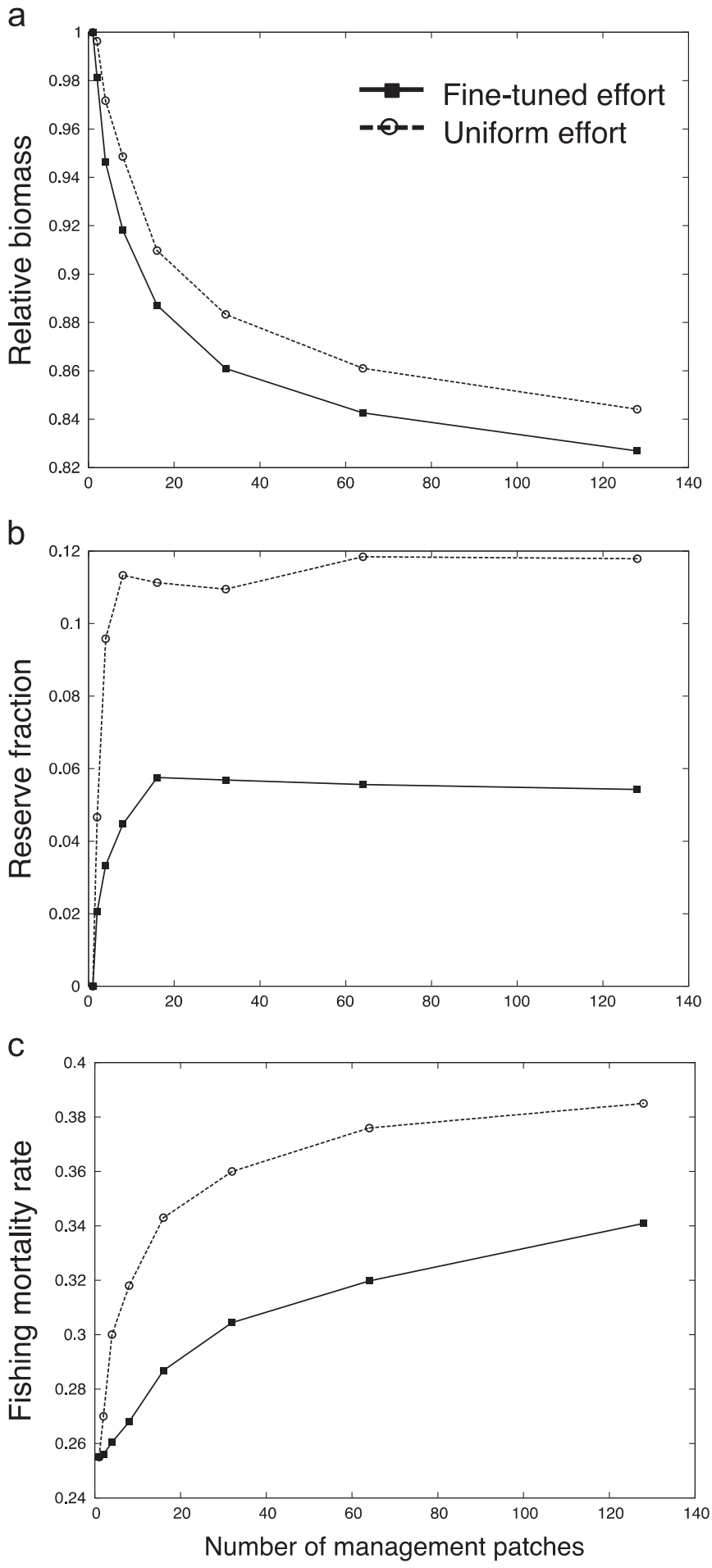

Fig. 3. The effect of management scale on biomass and management controls in an autocorrelated landscape ( $\phi_{1}=0.9$ ) with the FE strategy (squares, solid line) or the UE strategy (circles, dashed line). Each panel shows (a) biomass relative to its value given one management patch, (b) reserve fraction, defined as [the number of reserves]/[the number of habitats], and (c) fishing mortality rate for the UE strategy and average fishing mortality rate over non-reserve patches for the FE strategy. These results are the average value of the 100 times simulation.

rapid for an autocorrelated landscape than an uncorrelated landscape, where the decline is nearly linear.

The qualitative trends described above are consistent for different values of settler survival, fishing effort cost, and natural mortality (Fig. S1) as well as for red abalone parameter values (Figs. S2 and S3). 
a
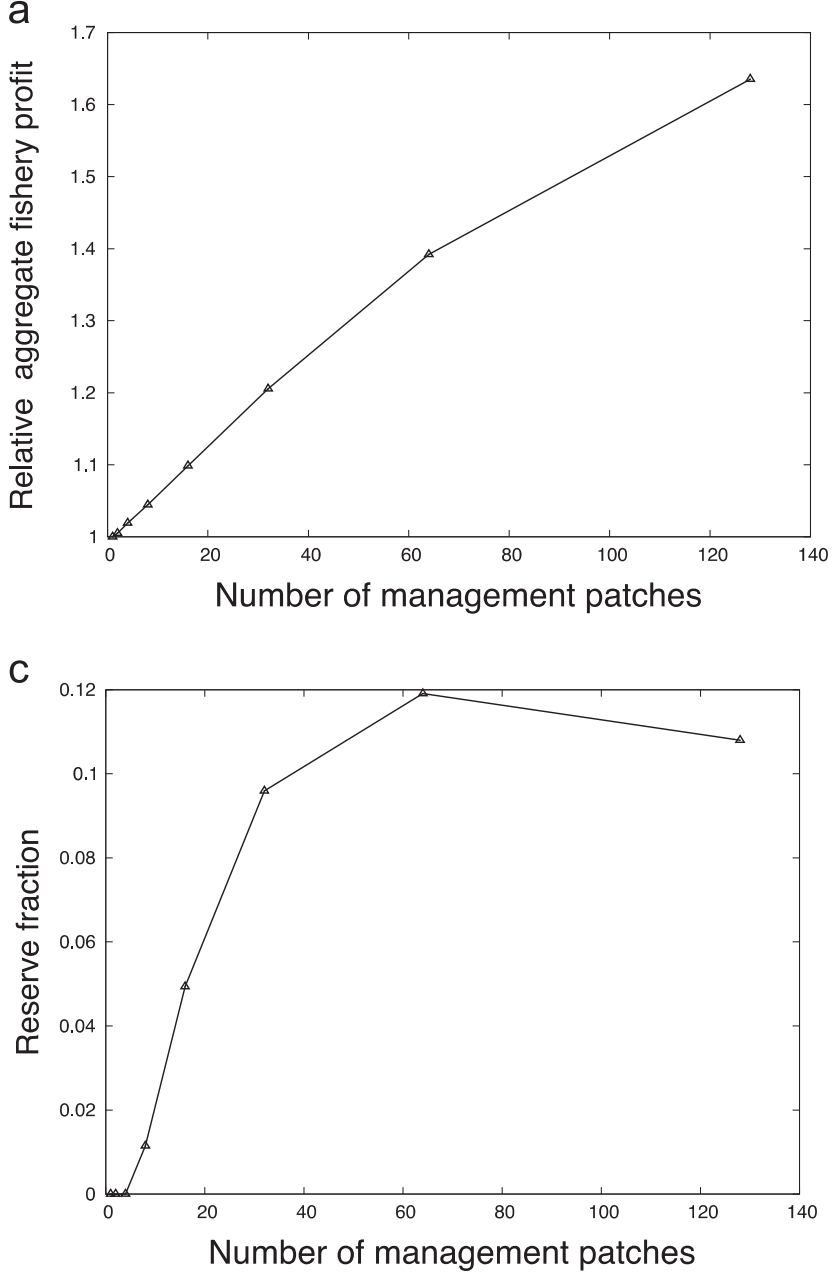

b

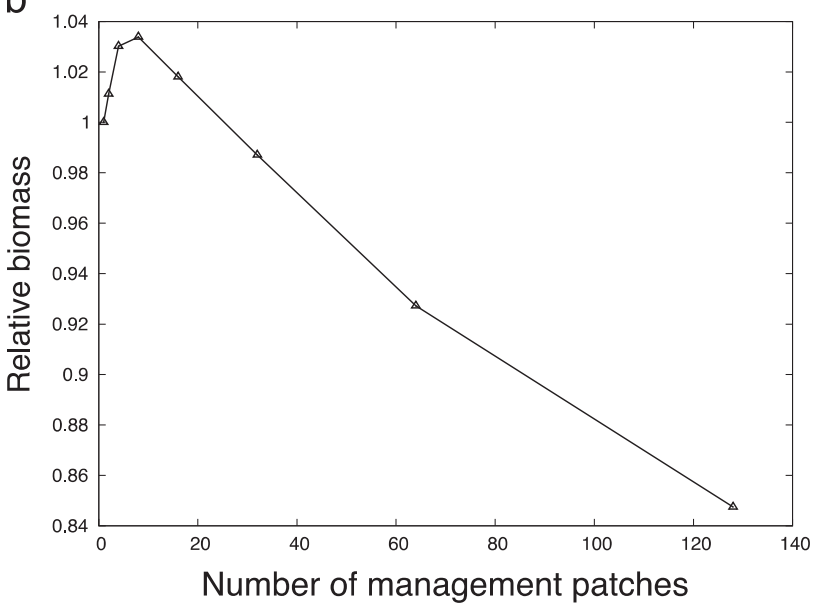

d

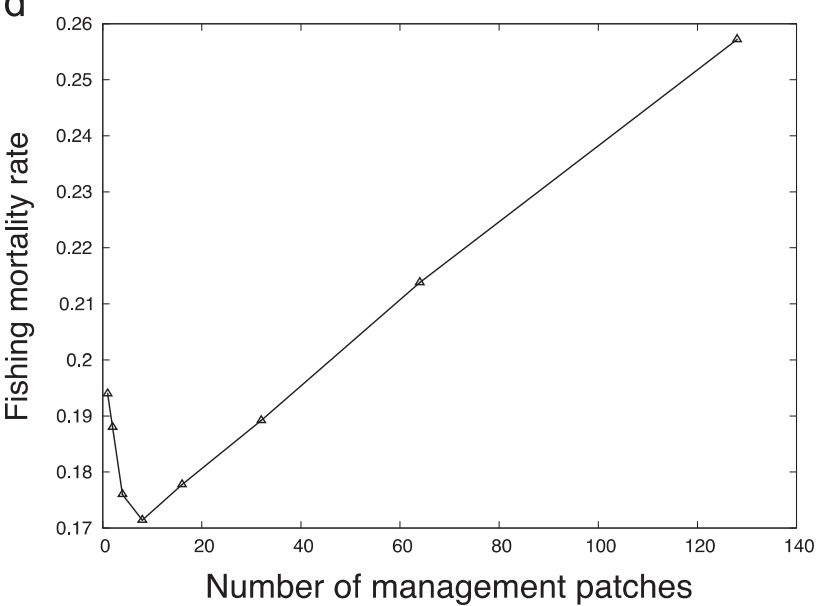

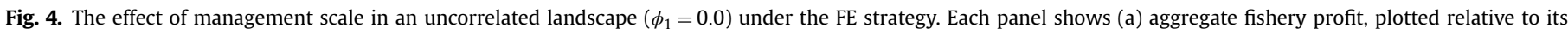

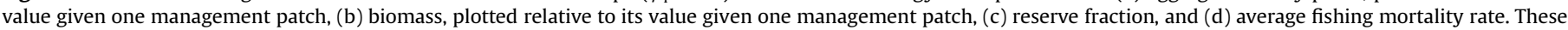
results are the average value of the 100 times simulation.

We assumed the total patch number is 128 and show the average value of the 100 simulation trials, and we verified that 100 trials were sufficient to capture the qualitative trends that drive our conclusions (Appendix S5; Fig. S5a). Note that, however, some effects of the stochasticity in habitat landscape generation remain, which arise from randomly-drawn habitat landscapes with either a large number or small number of habitat patches. Each trial shows quantitatively different results in the values of our output metrics, while the relative values across different management scales typically hold in each trial. The variability in the number of habitat patches of the landscape particularly affects the reserve fraction because the number of reserves primarily depend on the number of habitat patches in the landscape, which causes the within-trend fluctuations in Fig. 3b (see Fig. S5b).

\section{Discussion}

Assuming no cost to management subdivision, fishery profit increases with increasing management patches due to increased flexibility in spatial management. However, the shape of this relationship (which determines the potential for an intermediate peak in profit with management scale given cost to subdivision; discussed below) depends critically on the degree of autocorrelation in the natural habitat. Specifically, profit saturates rapidly with the number of subdivisions with autocorrelation but increases in a near linear relationship without autocorrelation (Figs. 2a and 4a). A landscape with positive autocorrelation is more clustered and hence contains larger-sized habitat patches. On the other hand, in uncorrelated landscapes individual habitat patches tend to be dispersed more evenly and averaged habitat size is smaller. Therefore, a finer filter is needed for spatial management in uncorrelated landscapes than autocorrelated landscape to achieve an effective allocation of fishing effort and marine reserves. In other words, if the same management scale is applied, managers inevitably place the fishing effort in a larger amount of unprofitable patches with uncorrelated landscapes than with autocorrelated landscapes (Fig. 5). Given these contrasting relationships, the incremental improvement with increasing the number of subdivisions exhibits diminishing returns for autocorrelated habitats (Fig. 2a) but is consistent across values for management scale in uncorrelated habitats (Fig. 4a).

Given the same degree of autocorrelation in landscapes, fisheries outcomes show qualitatively similar results between two different fishing strategies, the optimized effort allocation (FE) strategy and the uniform effort allocation (UE) strategy (Figs. 2 and 3) which indicates robustness of our results to different fishing approaches. However, in the FE strategy results in greater profit with lower fishing effort and lower population biomass and reserve fraction compared to the UE strategy: the FE strategy allows fishermen to increase fishery profit more effectively through the fine-tuned effort allocation and consequently it causes a larger decline in the biomass in comparison with the UE strategy. Regardless of the 


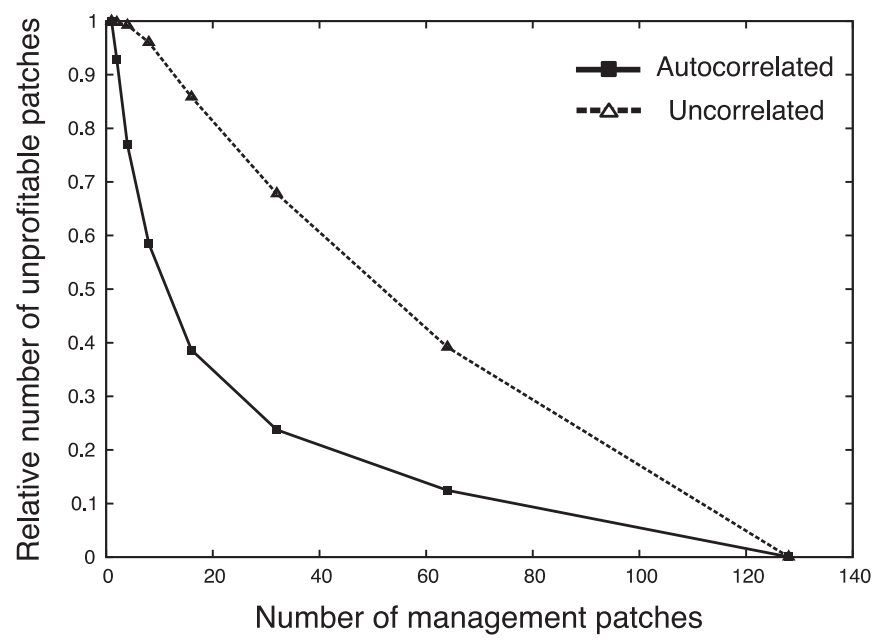

Fig. 5. The number of unprofitable patches in the optimal effort allocation under the FE strategy. They are plotted relative to the number given one management patch, as a function of the environmental scale both in an autocorrelated landscape ( $\phi_{1}=0.9$, box, thick line) and an uncorrelated landscape $\left(\phi_{1}=0.0\right.$, triangle, dashed line).

optimal zonal allocation of fishing effort, marine reserves are typically a part of optimal management, corresponding to previous models (Neubert, 2003; Sanchirico et al., 2006), because the variability in habitat quality, in combination with dispersal, leads to patches where fishing is unprofitable (Fig. 5).

\subsection{The effect of management context}

We ignore any potential costs of finer management such as management costs and transaction costs (Naidoo et al., 2006) because of the uncertainty and variability of such costs. Whether increasing cost with management scale leads to a maximum net fishery benefit (aggregate fishery profit minus costs following subdivisions) at an intermediate management scale will depend on the shape of the cost function (e.g., linear, exponential, or saturating relationship) compared to the autocorrelation-driven shape of the profit curve. For example, under the simplest possible case of a linear increase in cost with management scale, the maximum net fishery benefit is more likely to occur at an intermediate management scale for fisheries in an autocorrelated landscape (Fig. S4a; with its saturating profit function vs. scale relationship) than an uncorrelated landscape (Fig. S4b; with its near linear profit function vs. scale relationship, such that the resulting net benefit function will also be linear; see Appendix S3 for a detailed explanation).

The cost of coarser scale management in our model arises from the potential to assign fishing effort to unprofitable environmental patches, including non-habitat patches. However, note that the profit in any management unit is always nonnegative $\left(\pi_{i, t} \geq 0\right)$ under the optimal fishing strategies. Targeting of unprofitable locations may occur in reality due to ineffective initial searching by fishers for the harvested stock in a broader management region. Learning which regions are productive versus unproductive might be particularly slow, and therefore costly, if fishers do not share information (Allen, 2000) or population abundance varies in time.

In our model, this inefficiency is higher in the management with a coarser scale and it approaches to zero as the management scale becomes finer (Fig. 5). Explicitly incorporating the cost associated with the gap between ecological and management scales would require accounting for factors such as fisher behavior and institutional cooperation (Hilborn et al., 2005).

Ownership among management patches is also an important factor determining the relationship between fishery profit and management scale. White and Costello (2011) investigated the effect of size of the management unit for territorial user rights fisheries (TURF, i.e., management unit) with a two-patch model consisting of homogeneous environment. They concluded that optimal harvesting with sustainable, maximized yield occurs if all fish stay within TURF boundaries, such that TURF owners fully "own" all fish within their respective territories. This requires very small fish movement and/or very large TURF size, where any increase in fish mobility or decrease in TURF size that increases fish movement outside the TURF boundaries reduces ownership; if extreme, this reduced ownership can lead to overharvesting. Clearly, the difference the larger optimum management unit of White and Costello (2011) and our increasing profit with smaller management units is due to their incorporation of competition among fishermen, where assured ownership over the management unit determines the management success. In contrast, here we model the dynamics that would occur under federal level decision-making, cooperative management, or sole ownership, where competition among fishermen does not occur.

Some fishery management regimes have a hierarchical allocation of fishing effort where each decision-making sector has different management scales. For example, in Japanese and Chilean TURF system, federal level regulations in each management unit could further be arranged among local fishermen by a finer management unit (Makino and Matsuda, 2005; Cancino et al., 2007). In fact, Hilborn et al. (2005) noted that the hierachical allocation of fishing effort caused serial depletion and collapse of California's abalone fisheries. Namely, state-level regulations create highly heterogeneous fishing pressure in the fishing ground, generating a mixture of depleted local populations and lightly exploited populations (Richards and Davis, 1993; Karpov et al. 2000). The optimal spatial scale of management under such hierarchical management regimes, a management approach in between our analysis and White and Costello (2011), will ultimately depend on the combination of incentives at both the individual and federal levels. Note that hierarchical scales could be incorporated into our model, such as by applying zero fishing effort to a large cluster of non-habitat patches but allocating effort more finely in other patches in the FE strategy. If we allow a management strategy to apply heterogeneous management unit scales, the additional dimension to optimize over would likely lead to faster initial increases in, and earlier diminishing returns for, aggregate fishery profit as a function of the number of subdivisions.

Beyond reserves and harvested zones, small-scale spatial management has been increasingly relevant to marine systems (Shepherd, 2003; Hilborn et al., 2005; Sanchirico and Wilen, 2005). Marine population dynamics often occur on smaller spatial scales than the typical commercial fishery management scale of hundreds to thousands of kilometers inherent to regulatory institutions (Hilborn et al., 2005). A system of co-management, where the government and individual fishers both contribute to management decisions and implementation (Pomeroy and Williams, 1994; Pomeroy and Berkes, 1997), would lead a finer management scale that better matches the biologically relevant scale and therefore can increase fishery profit, as suggested by our results. For example, in the co-managed Japanese TURF system, local communities submit individual management plans to the Prefecture for regional-level coordination (Hilborn et al., 2005).

Information availability can also affect optimal fisheries management and social decision-making (Andelman and Willig, 2002; Richardson et al., 2006). We assumed implicitly perfect knowledge of managers in our model, as is often the case where managers intend to optimize the management outcomes based on metrics such as habitat quality (Neubert, 2003; Sanchirico and Wilen, 2005). Our model is most relevant to the situation where managers have a high degree of geographic and biological information. A high degree of information might be more common in systems of co- 
management, where fishermen typically collect finer-scale fisheries information because of the local-level management (Pomeroy and Berkes, 1997), than the case of stock-level management modeled here. For example, in the case of fishing cooperative associations (FCA) in Japan (i.e., a co-management fishery), local, regional, and national governmental coordination in the design and implementation of fishery regulations (Lim et al., 1995) may allow a stock-level management institution to acquire fine resolution geographic and biological information. Technological innovations in marine spatial management can also facilitate collection of fine resolution data by a stock-level management institution. For example, remote sensing can map important ocean processes that influence species distributions, and geographic information systems (GIS) technology can help identify locations with essential habitat (Valavanis et al., 2004, 2008). More typically, given imperfect knowledge of demographic and biological parameters, our model might overestimate fishery profits, especially when managers apply a fine management scale, because of uncertainties in choosing appropriate patches. In this case, another trade-off, between flexible management and optimization errors, might arise.

\subsection{Conservation vs. fishery management goals}

Our analysis shows the significance of the choice of management scale in spatial fishery management: applying a different spatial scale of management alters the outcome for both in economic and ecological metrics, such as fishery profit, reserve fraction, fishing mortality rate, and population biomass. Specifically, a finer management scale allows fishermen to increase fishery profit effectively, but it causes a larger decline in biomass because of the more fine-tuned fishing (Figs. 3 and 4 ), showing a trade-off between economic values versus conservation value in spatial planning (also observed in White et al., 2012; Rassweiler et al., 2014). Hence, a careful consideration of both management goals and management scale is crucial for management success.

\section{Acknowledgments}

This work was supported by Grant-in-Aid for Japan Society for the Promotion of Science (JSPS) Fellows to NT. We were also supported by Global Center of Excellence (GCOE) Program entitled "Asian Conservation Ecology as a basis of human-nature mutualism”, JSPS. We thank N. Kumagai, L. W. Botsford, Y. Imai, H. Yokomizo, M. Springborn, J. N. Sanchirico, and Y Iwasa for their thoughtful comments.

\section{Appendix A. Supplementary material}

Supplementary data associated with this article can be found in the online version at http://dx.doi.org/10.1016/j.jtbi.2015.11.005.

\section{References}

Allen, P.M., 2000. Knowledge, Ignorance, and Learning. A J. Emergence, Complex. \& Organ. Manag. 2 (46), 78-103.

Andelman, S.J., Willig, M.R., 2002. Alternative configurations of conservation reserves for Paraguayan bats: considerations of spatial scale. Conserv. Biol. 16, 1352-1363.

Botsford, H., Hastings, A., Gaines, S., 2001. Dependence of sustainability on the configuration of marine reserves and larval dispersal distance. Ecol. Lett. 4, 144-150.

Cancino, J., Uchida, H., Wilen, J., 2007. TURFs and ITQs: collective vs. individual decision making. Mar. Resour. Econ. 22, 391-406.
CDFW (California Department of Fish and Wildlife), 2014a. Current California Ocean Recreational Fishing Regulations. 〈https://www.dfg.ca.gov/marine/mapregs4. asp $>$.

CDFW (California Department of Fish and Wildlife), 2014b. California Marine Life Protection Act Initiative Regional Profile of the North Coast Study Region (California-Oregon Border to Alder Creek). 〈http://www.dfg.ca.gov/marine/ mpa/ncprofile.asp $\rangle$.

Cope, J.M., Punt, A.E., 2005. Status of Cabezon (Scorpaenichthys marmoratus) in California Waters as Assessed in 2005. Pacific Fishery Management Council, Portland, Oregon.

Dale, M.R.T., Fortin, M.-J., 2009. Spatial autocorrelation and statistical tests: some solutions. J. Agric. Biol. Environ. Stat. 14, 188-206.

Dougherty, D.T., Hilborn, R., Punt, A.E., Stewart, I.J., 2013. Modeling co-occurring species: a simulation study on the effects of spatial scale for setting management targets. Can. J. Fish. Aquat. Sci. 70, 49-56.

Francis, R.C., 1986. Two fisheries biology problems in west coast groundfish management. N. Am. J. Fish. Manag. 64, 453-462.

Francis, R.C., Hixon, M.A., Clarke, M.E., Murawski, S.A., Ralston, S., 2007. Ten commandments for ecosystem-based fisheries scientists. Fisheries 32, 217-233.

Hilborn, R., Orensanz, J.M.L., Parma, A.M., 2005. Institutions, incentives and the future of fisheries. Philos. Trans. R. Soc. Lond. Ser. B, Biol. Sci. 360, 47-57.

Hopkinson, P., Evans, J., Gregory, R.D., 2000. National-scale conservation assessments at an appropriate resolution. Divers. Distrib. 6, 195-204.

Hurlbert, A.H., Jetz, W., 2007. Species richness, hotspots, and the scale dependence of range maps in ecology and conservation. Proc. Natl. Acad. Sci. U.S.A 104, 13384-13389.

Kaplan, D.M., 2006. Alongshore advection and marine reserves: consequences for modeling and management. Mar. Ecol. Prog. Ser. 309, 11-24.

Karpov, K.A., Haaker, P.L., Taniguchi, I.K., Rogers-Bennett, L., 2000. Serial depletion and the collapse of the California abalone ( Haliotis spp.) fishery. Pages 11-24 Workshop on Rebuilding Abalone Stocks in British Columbia.

Leslie, H., 2005. A synthesis of marine conservation planning approaches. Conserv. Biol. 19, 1701-1713.

Lester, S., Halpern, B., Grorud-Colvert, K., 2009. Biological effects within no-take marine reserves: a global synthesis. Mar. Ecol. Progress Ser. 384, 33-46.

Levin, S.A., 1992. The problem of pattern and scale in ecology: the Robert $H$, MacArthur award lecture. Ecology 73, 1943-1967.

Lim, C.P., Matsuda, Y., Shigemi, Y., 1995. Co-management in marine fisheries: the Japanese experience. Coast. Manag. 23, 195-221.

Lockwood, D.R., Hastings, A., Botsford, L.W., 2002. The effects of dispersal patterns on marine reserves: does the tail wag the dog? Theor. Popul. Biol. 61, 297-309.

Makino, M., Matsuda, H., 2005. Co-management in Japanese coastal fisheries: institutional features and transaction costs. Mar. Policy 29, 441-450.

Margules, C.R., Pressey, R.L., 2000. Systematic conservation planning. Nature 405, $243-253$.

Naidoo, R., Balmford, A., Ferraro, P.J., Polasky, S., Ricketts, T.H., Rouget, M., 2006 Integrating economic costs into conservation planning. Trends Ecol. Evol. 21, 681-687.

Neubert, M., 2003. Marine reserves and optimal harvesting. Ecol. Lett. 6, 843-849.

O'Connell, C.P., 1953. The Life History of the Cabezon Scorpaenichthys marmoratus ( Ayres ). Fish. Bull., 76.

Palmer, M., White, P., 1994. Scale dependence and the species-area relationship. Am. Nat., 717-740.

Pikitch, E.K., Santora, E.A., Babcock, A., Bakun, A., Bonfil, R., Conover, D.O., Dayton, P., Doukakis, P., Fluharty, D., Heneman, B., Houde, E.D., Link, J., Livingston, P.A. Mangel, M., McAllister, M.K., Pope, J., Sainsbury, K.J., 2004. Ecosystem-based fishery management. Science 305, 346-347.

Pomeroy, R.S., Berkes, F., 1997. Two to tango: the role of government in fisheries comanagement. Mar. Policy 21, 465-480.

Pomeroy, R.S., Williams, M.J., 1994. Fisheries Co-management and Small-scale Fisheries. A Policy Brief.

Rassweiler, A., Costello, C., Hilborn, R., Siegel, D., 2014. Integrating scientific guidance into marine spatial planning. Proc. Biol. Sci./R. Soc. 281, 20132252.

Rassweiler, A., Costello, C., Siegel, D., 2012. Marine protected areas and the value of spatially optimized fishery management. Proc. Natl. Acad. Sci. U.S.A 109, 11884-11889.

Richards, D.V., Davis, G.E., 1993. Early warnings of modern population collapse in black abalone Haliotis cracherodii, Leach, 1814 at the California Channel Islands. J. Shellfish Res. 12, 189-194.

Richardson, E.A., Kaiser, M.J., Edwards-Jones, G., Possingham, H.P., 2006. Sensitivity of marine-reserve design to the spatial resolution of socioeconomic data. Conserv. Biol. 20, 1191-1202.

Sanchirico, J.N., Malvadkar, U., Hastings, A., Wilen, J.E., 2006. When are no-take zones an economically optimal fishery management strategy? Ecol. Appl. 16, 1643-1659.

Sanchirico, J.N., Wilen, J.E., 2005. Optimal spatial management of renewable resources: matching policy scope to ecosystem scale. J. Environ. Econ. Manag. $50,23-46$.

Schwartz, M.W., 1999. Choosing the appropriate scale of reserves for conservation. Annu. Rev. Ecol. Syst. 30, 83-108.

Shepherd, J.G., 2003. Fishing effort control: could it work under the common fisheries policy? Fish. Res. 63, 149-153.

Turner, W., Tjørve, E., 2005. Scale-dependence in species-area relationships. Ecography $28,721-730$. 
Valavanis, V.D., Georgakarakos, S., Kapantagakis, A., Palialexis, A., Katara, I., 2004. A GIS environmental modelling approach to essential fish habitat designation. Ecol. Model. 178, 417-427.

Valavanis, V.D., Pierce, G.J., Zuur, A.F., Palialexis, A., Saveliev, A., Katara, I., Wang, J., 2008. Modelling of essential fish habitat based on remote sensing, spatial analysis and GIS. Hydrobiologia 612, 5-20.

White, C., Costello, C., 2011. Matching spatial property rights fisheries with scales of fish dispersal. Ecol. Appl. 21, 350-362.
White, C., Halpern, B.S., Kappel, C.V., 2012. Ecosystem service tradeoff analysis reveals the value of marine spatial planning for multiple ocean uses. Proc. Natl. Acad. Sci. U.S.A 109, 4696-4701.

White, J.W., Botsford, L.W., Moffitt, E.A., Fischer, D.T., 2010. Decision analysis for designing marine protected areas for multiple species with uncertain fishery status. Ecol. Appl. 20, 1523-1541. 


\section{Exploring the effect of the spatial scale of fishery management}

2 Nao Takashina, Marissa L. Baskett

3

4 Supplementary Information

5

6 Appendix S1: Optimization of the aggregate fishery profit

$7 \quad$ Here we describe the heuristic algorisms used to obtain local maximum fishery

8 profit in each landscape for a given management scale.

10 (i) Uniformed effort strategy

11 The uniformed effort strategy (UE strategy) achieves an optimization of aggregate

12 fishery profit by choosing $2^{n}+1$ parameters together so as to maximize the objective

13 function at equilibrium $\Pi_{2^{n}}^{*}=\sum \pi_{i}^{*}$, where $2^{n}$ is the number of management patches and

$14 i$ represents the environmental patch. First, $2^{n}$ binary parameters $\left(A_{1}, A_{2}, \cdots, A_{2^{n}}\right)$

15 represent a reserve or fishing ground in each management patch, and the additional

16 parameter $F$ represents the intensity of the fishing effort applied to all fishing grounds. For

17 each value of intensity of fishing effort $F$, we calculate an optimal set of reserves and 
18 fishing grounds allocation $\left(A_{1}, A_{2}, \cdots, A_{2^{n}}\right)$, and finally we select the set of

$19\left(A_{1}, A_{2}, \cdots, A_{2^{n}}, F\right)$ that shows the highest equilibrium aggregate fishery profit. We start

20 with $F=0.1$ and increase $F$ by an increment of 0.1 unless optimized fisheries profit goes

21 to 0 . We attain an optimal allocation of reserves and fishing grounds $\left(A_{1}, A_{2}, \cdots, A_{2^{n}}\right)$ by

22 applying the greedy algorithm, a procedure in which we start with each management patch

23 designated randomly as either a reserve or fishing ground and then search across all of the

24 management patches from the first management patch until we find a case in which

25 switching a patch's designation increases the aggregate profit. After making this switch, we

26 repeat the same procedure from the first management patch until we find an allocation of

27 fishing grounds and reserves where no switch increases the aggregate fishery profit,

28 following Rassweiler et al. (2012). We maintain $\Pi_{2^{n+1}}^{*} \geq \Pi_{2^{n}}^{*}$ by imposing multiple

29 simulation runs if the condition is not satisfied. Comparison with other heuristic algorithms

30 is discussed in more detail in Rassweiler et al. (2012).

31

32 (ii) Fine-tuned effort strategy 
34 above, we attain an optimization of the aggregate fishery profit under fine-tuned effort

35 strategy (FE strategy) by choosing $2^{n}$ parameters $\left(F_{1}, F_{2}, \cdots, F_{2^{n}}\right)$, where $2^{n}$ is the

36 number of management patches and $F_{i}$ represents fishing effort in management patch $i$.

37 To find the optimal values of $\left(F_{1}, F_{2}, \cdots, F_{2^{n}}\right)$, we apply an analogue of the greedy

38 algorithm and a local search algorithm with, if necessary, multiple trials with different

39 initial conditions. We start with each management patch having a fishing effort level

40 assigned from an independent and identically distributed random variable with range

$41 F_{i} \in[0,1]$ with 0.1 step size, and we impose an amount and/or decrement of the intensity

42 of fishing effort by an increment of 0.1 upon the first management patch and search across

43 all of the management patches until we find a case in which an increment and/or decrement

44 of the intensity of fishing increases the aggregate profit. Then we make the switch and

45 repeat the same procedure from the first management patch until finding final allocation of

46 fishing effort $\left(F_{1}, F_{2}, \cdots, F_{2^{n}}\right)$ where no switch improves the aggregate profit. In addition

47 to the condition $\Pi_{2^{n+1}}^{*} \geq \Pi_{2^{n}}^{*}$, we maintain $\Pi_{2^{n}}^{*}$ of the FE strategy $\geq \Pi_{2^{n}}^{*}$ of the UE 
48 strategy by imposing multiple simulation runs if these conditions are not satisfied.

\section{References}

51 Rassweiler, A., C. Costello, and D. A. Siegel. 2012. Marine protected areas and the value 52 of spatially optimized fishery management. Proceedings of the National Academy of 53 Sciences 109:11884-11889.

54

55 Table S1 Red abalone (Haliotis rufescens) parameters. The same parameter values are used

56 in the analysis in White et al. (2010). 


\begin{tabular}{|c|c|c|c|}
\hline Parameter & Description & Value & Source* \\
\hline$L_{\infty}$ & Maximum size & $19.24 \mathrm{~cm}$ & a \\
\hline$k$ & Growth rate & $0.2174 \mathrm{~cm} /$ year & $\mathrm{a}$ \\
\hline$a_{0}$ & Age at $0 \mathrm{~cm}$ & 0 year & a \\
\hline \multirow[t]{2}{*}{$b_{1}$} & Coefficient in length-to-weight & $1.69 \times 10^{-4}$ & $\mathrm{~b}$ \\
\hline & relationship & & \\
\hline \multirow[t]{2}{*}{$b_{2}$} & Exponent in length-to-weight & 3.02 & $\mathrm{~b}$ \\
\hline & relationship & & \\
\hline$E_{a}$ & Fecundity-at-length & $15.32 L_{a}^{4.518}$ eggs & c \\
\hline$a_{\max }$ & Maximum age & 30 years & $\mathrm{d}$ \\
\hline$a_{\text {mat }}$ & Age at maturity & 3 years & $\mathrm{e}$ \\
\hline$a_{\text {catch }}$ & Age available to fishing & 8 years $(17.8 \mathrm{~cm})$ & $\mathrm{f}$ \\
\hline$M$ & Natural mortality rate & $0.15 /$ year & $\mathrm{g}$ \\
\hline $\bar{m}$ & Mean larvae dispersal distance & $5 \mathrm{~km}$ & $\mathrm{f}, \mathrm{h}$ \\
\hline
\end{tabular}


$57 *$ Sources:

58 (a) Tegner, M. J., DeMartini, J. D. \& Karpov, K. A. (1992). The California red abalone: a

59 case study in complexity. In: Abalone of the world: biology, fisheries, and culture. (ed.

60 Shepherd, S. A., Tegner, M. J. \& Guzman del Proo, S. A.). Blackwell Science, Oxford, pp.

$61 \quad 370-383$.

62 (b) Ault, J. S. (1982). Aspects of laboratory reproduction and growth of the red abalone,

63 Haliotis rufescens Swainson (Doctoral dissertation, Humboldt State University).

64 (c) Hobday, A. J. \& Tegner, M. J. (2002). The warm and the cold: Influence of temperature

65 and fishing on local population dynamics of red abalone. Cal. Coop. Ocean. Fish., 43,

66 74-96.

67 (d) Leaf, R. T. (2005). Biology of the red abalone, Haliotis rufescens, in Northern

68 California (Doctoral dissertation, San Jose State University).

69 (e) Rogers-Bennett L., Allen, B. L. \& Davis G. E. (2004). Measuring abalone (Haliotis

70 spp.) recruitment in California to examine recruitment overfishing and recovery criteria. $J$.

71 shellfish res., 23, 1201-1207. 
72 (f) White, J.W., Botsford, L.W., Moffitt, E.A. \& Fischer, D.T. (2010). Decision analysis for

73 designing marine protected areas for multiple species with uncertain fishery status. Ecol.

74 Appl., 20, 1523-1541.

75 (g) Tegner, M. J., Breen, P. A. \& Lennert, C. E. (1989). Population biology of red abalone,

76 Haliotis rufescens, in southern California and management of red and pink, H. corrugata,

77 abalone fisheries. Fish. Bull., 87, 295-339.

78 (h) Sasaki, R. \& Shepherd, S. A. (1995). Larval dispersal and recruitment of Haliotis discus

79 hannai and Tegula spp. on Miyagi Coasts, Japan. Mar. Freshwater Res., 46, 519-29.

80 


\section{Appendix S2: Sensitivity analysis}

82 Here we show the results of a sensitivity analysis focused on the parameters with

83 the greatest expected uncertainty (Fig. S1) and the results for the second species tested,

84 namely Red Abalone (Haliotis rufescens; Figs. S2 and S3). The qualitative trends

85 highlighted in the main text, such as the diminishing returns in aggregate fishery profit with

86 finer management scale given habitat autocorrelation, are consistent across species and

87 parameter values.

88 
(a) Maximum settler survival rate

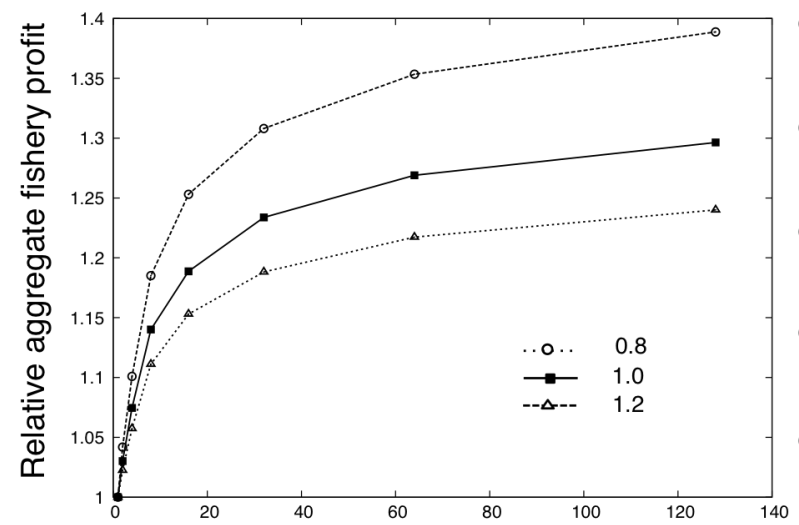

(b) Cost of fishing effort

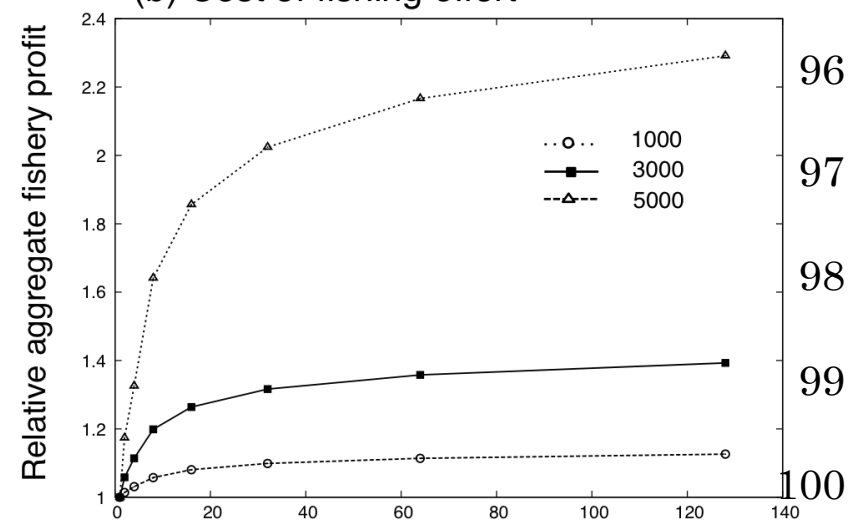

(c) Natural mortality

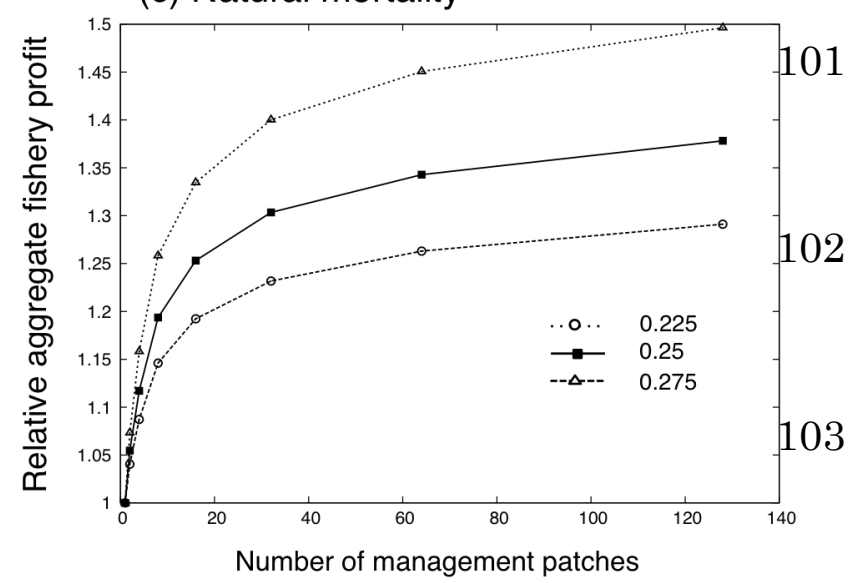

Figure S1 Dependence of the

91 relative aggregate fishery profit in

92 an autocorrelated landscape

$93\left(\phi_{1}=0.9\right)$ under the FE strategy,

94 plotted relative to its value given

95 one management patch, on (a)

96 maximum settler survival rate $\alpha$,

97 (b) cost of fishing effort $c$, and (c)

98 natural mortality $M$. Red lines represents the value used in the main text. 
(a)

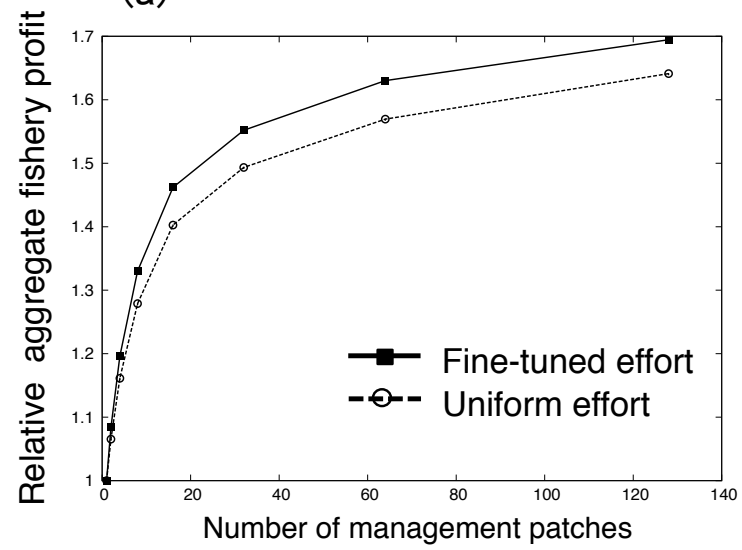

(c)

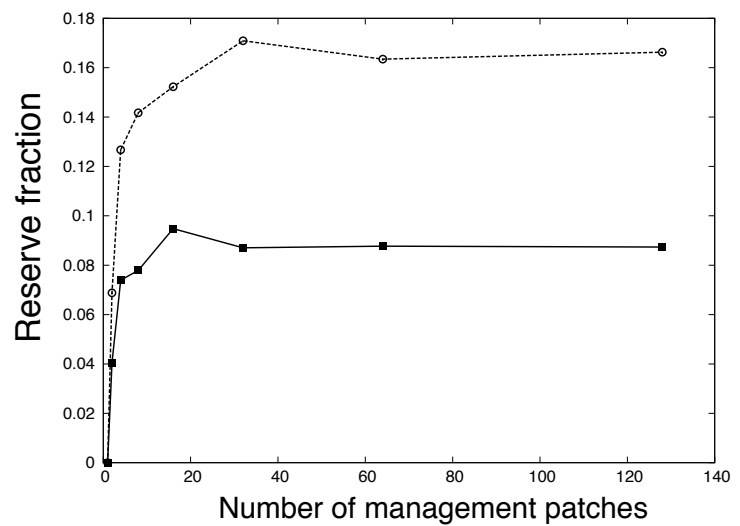

(b)

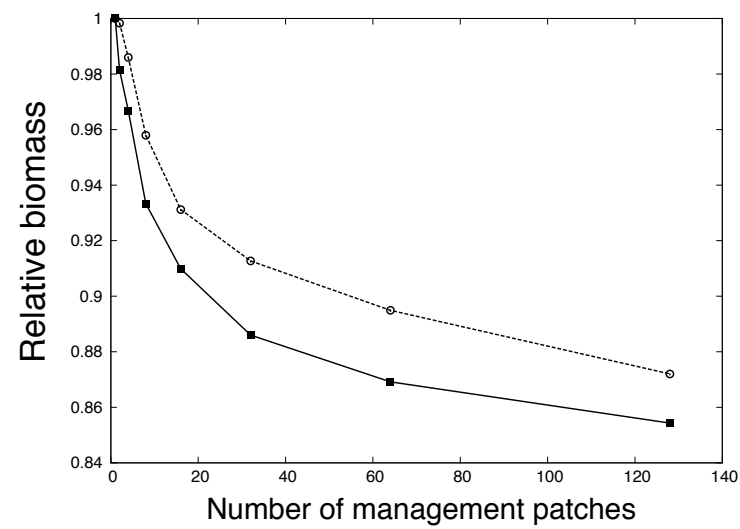

(d)

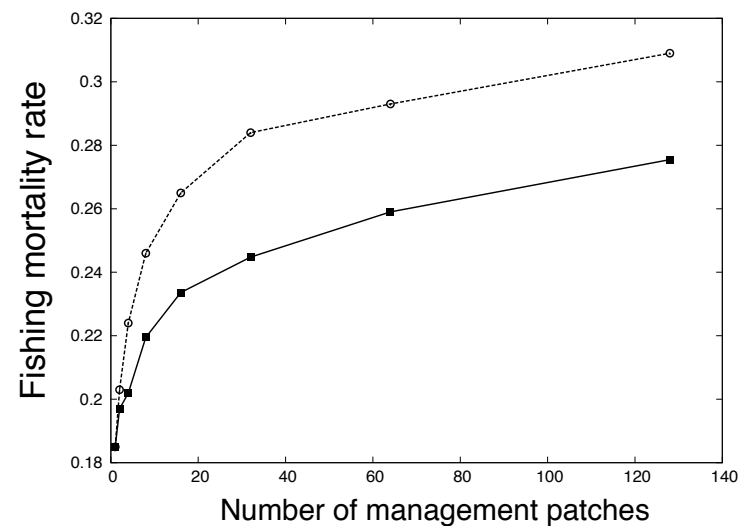

106 Figure S2 The effect of management scale on red abalone (Haliotis rufescens) in an

107 autocorrelated landscape under the FE strategy (squares, solid line) or the UE strategy

108 (circles, dashed lines). Each panel shows (a) aggregate fishery profit, plotted relative to its

109 value given one management patch, (b) biomass, plotted relative to its value given one

110 management patch, (c) reserve fraction, and (d) average fishing mortality rate. 


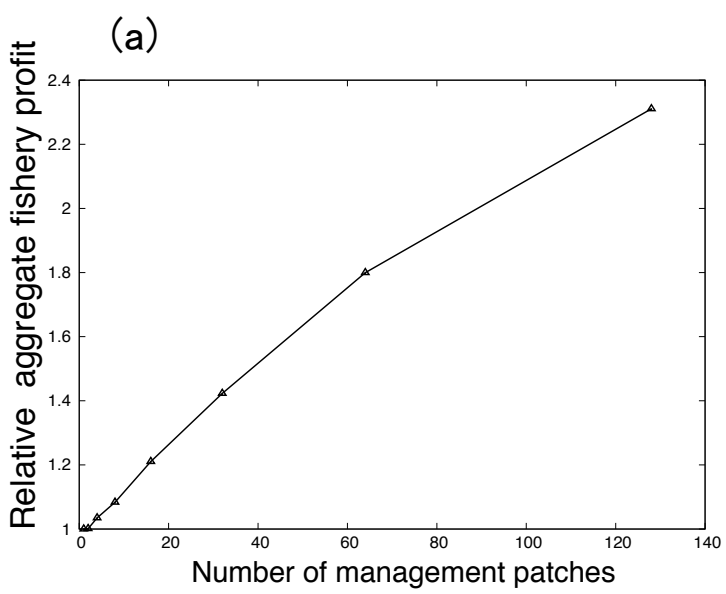

(c)

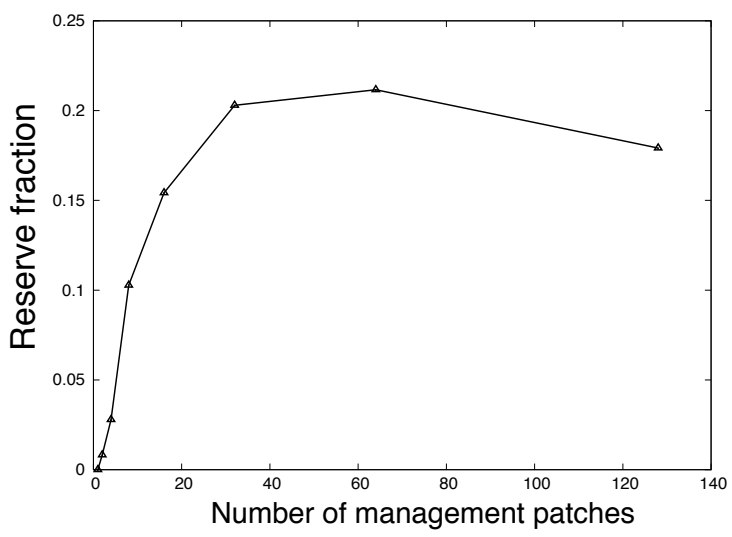

(b)

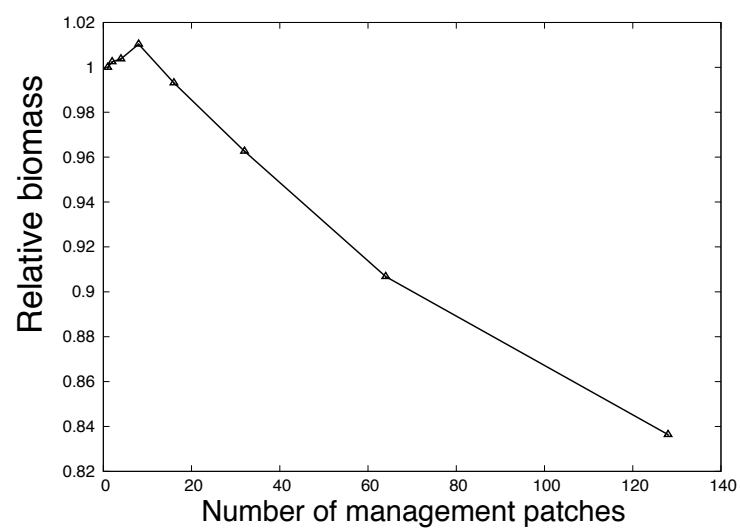

(d)

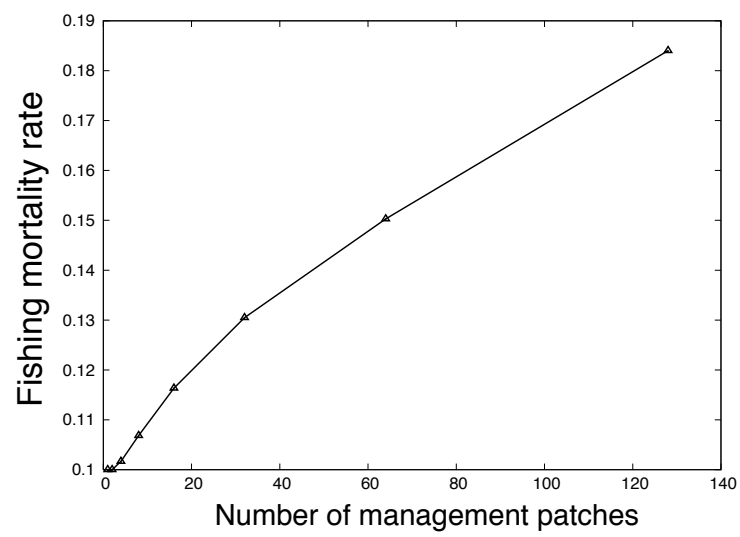

112

113 Figure S3 The effect of management scale on red abalone (Haliotis rufescens) in an

114 uncorrelated landscape under FE strategy. Each panel shows (a) aggregate fishery profit,

115 plotted relative to its value given one management patch, (b) biomass, plotted relative to its

116 value given one management patch, (c) reserve fraction, and (d) average fishing mortality

117 rate.

118

119 


\section{Appendix S3: Derivation of cost}

management increases with the number of management patches and is static over time. We

123 may obtain a functional form $\alpha_{1} N^{\alpha_{2}}$ as an additional cost of spatial fishery management,

124 where $N$ is the number of management patches $(1 \leq N \leq 128$; see the main text) and both

$125 \alpha_{1}$ and $\alpha_{2}$ are $>0$. By subtracting this additional cost from Eq. 4 at equilibrium, we

126 arrive at a net fishery benefit at equilibrium of $\hat{\Pi}_{2^{n}}^{*}=\sum \pi_{i}^{*}-\alpha_{1} 2^{n \alpha_{2}}$, where $2^{n}$ is a feasible

127 number of management patches. Fig. S5 conceptually illustrates the net fishery benefit in

128 the case where $\alpha_{2}=1$, i.e., assuming that the aggregated fishery profit is a liner function of

129 the number of management patches $N$ in an uncorrelated landscape. In an autocorrelated

130 landscape, if a cost of management $\alpha_{1} 2^{n \alpha_{2}}$ exceeds an aggregate fishery profit $\sum \pi_{i}^{*}$ in

$1310<n \leq 7$, the curve of the net fishery benefit $\hat{\Pi}_{2^{n}}^{*}$ is likely to have an intermediate

132 optimum in the management scale that maximizes the net fishery benefit, $\hat{\Pi}_{2^{n}}^{*}$ (Fig. S5a).

133 Alternatively, in an uncorrelated landscape, the net fishery benefit does not have an

134 intermediate optimum (Fig. S5b). More generally (i.e., for all $\alpha_{2}>0$ ), in an uncorrelated 
135 landscape where the aggregated fishery profit is an approximately liner function of the

136 number of management patches $N$, we can describe the aggregated profit with slope $A_{1}$

137 and intercept $A_{2}: A_{1} N+A_{2}$. As defined above, the net fishery benefit is the aggregate

138 fishery benefit minus the additional cost: $\hat{\Pi}_{N}^{*}=A_{1} N+A_{2}-\alpha_{1} N^{\alpha_{2}}$. The second derivative of

139 the net fishery benefit is then $d \hat{\Pi}_{N}^{*} / d N^{2}=-\alpha_{1} \alpha_{2}\left(\alpha_{2}-1\right) N^{\alpha_{2}-2}>0$ for $0<\alpha_{2}<1$, and

140 therefore is a convex function (Boccara 1990), implying that there is no intermediate

141 optimum. In fact, the net fishery benefit can have a global maximum for $\alpha_{2}>1$ because of

142 the concavity as the above condition suggests, but not for $N \geq 1$ where our analysis is

143 focused. We can briefly explain this fact: In the domain $N \geq 1$ and for $\alpha_{2}>1$, the

144 additional cost is the lowest at $N=1$ and increases monotonically with $N$, and the net benefit

145 function $\hat{\Pi}_{N}^{*}$, which is a linearly increasing function minus a monotonically and

146 exponentially increasing function, is a monotonically decreasing function in $N \geq 1$,

147 implying that it does not have an intermediate optimum. Therefore, an intermediate

148 optimum in management scale given any cost to subdivision is unlikely to occur in an

149 uncorrelated landscape but is likely to occur in an autocorrelated landscape. 


\section{References}

152 Boccara, N. (1990). Functional Analysis: An Introduction for Physicists. Academic Press,

153 New York.

154

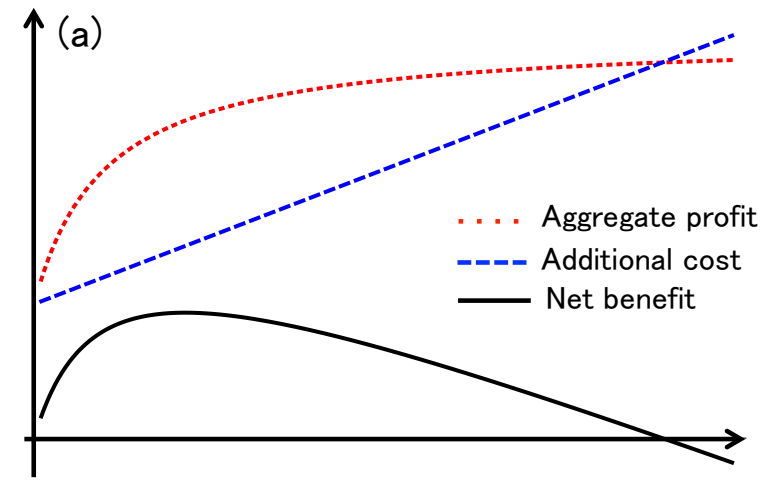

Number of management patches

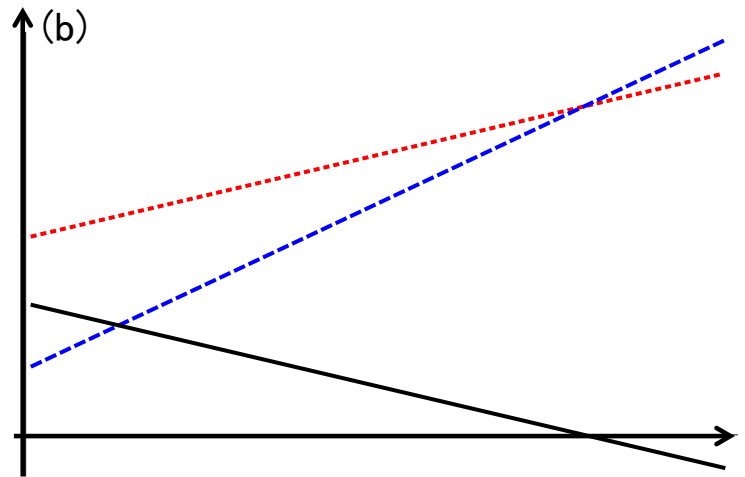

Number of management patches

156 Figure S4 Conceptual diagram of the net fishery benefit, which is the aggregate fishery

157 profit (dashed red lines) minus an additional cost (dashed blue lines). For illustration, we

158 assume that the cost of subdivision (dashed blue lines) increases linearly with an increasing

159 number of management patches (e.g., as might occur due to increasing enforcement costs).

160 (a) The net fishery benefit (solid black line) in an autocorrelated landscape has an

161 intermediate optimum given the saturating profit function (dashed red line). (b) The net

162 fishery benefit in an uncorrelated landscape does not have an intermediate optimum 
163 because the net benefit decreases monotonically with the number of management patches

164 (solid black line).

165 


\section{Appendix S4: Validity of the simulation settings}

167 Here we verify that the number of trials used in our simulations is sufficient to capture

168 qualitative trends. The qualitative relationship between aggregate fishery profit and the

169 number of management patches is consistent regardless of the number of simulation trials

170 used (25-150 trials), and the simulations converge in the range of the 100-trial results (Fig.

171 S4a). The rapidly saturating relationship between reserve fraction and the number of

172 management patches is consistent across realizations, while the variability within that

173 relationship represents the stochastic effects of habitat patch selection (Fig. S4b; see

174 Results: Management efficacy and parameter sensitivity).

175
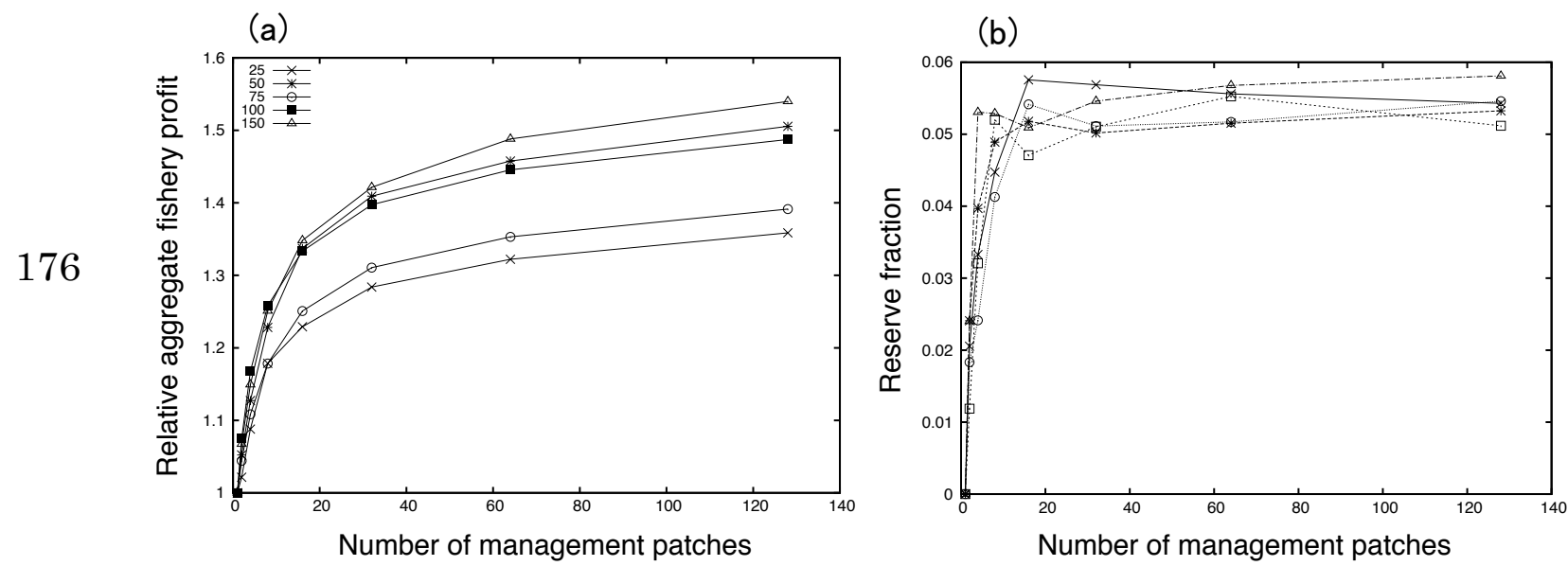

177 Figure S5 Verification that 100 simulation trials captures qualitative trends for the 
178 fine-tuned effort strategy. (a) Aggregate fishery profit in an autocorrelated landscape

$179\left(\phi_{1}=0.9\right)$ with various numbers of simulation trials. Each line, plotted relative to the value

180 given one management patch, shows the average value of simulation trials: 25 (cross), 50

181 (star), 75 (circle), 100 (box), and 150 (triangle). (b) Realizations of reserve fractions of the

182 five different hundred-time simulation trials.

183 